\title{
Ketamine versus dexmedetomidine as an adjuvant in ultrasound-guided supraclavicular brachial plexus block: A double-blind randomized clinical trial
}

Ahmed mohmed

Minia University

Abeer Hassanein

Minia University

Haidy Mansour ( $\sim$ haidy_mourad@yahoo.com )

Minia University

\section{Research Article}

Keywords: ketamine, dexmedetomidine, supraclavicular brachial plexus block, anesthesia

Posted Date: January 11th, 2021

DOI: https://doi.org/10.21203/rs.3.rs-128342/v1

License: (c) This work is licensed under a Creative Commons Attribution 4.0 International License.

Read Full License 


\title{
Ketamine versus dexmedetomidine as an adjuvant in ultrasound-guided supraclavicular brachial plexus block: A double-blind randomized clinical trial.
}

Ahmed Hassanein mohmed, MD, assistance professor in Anesthesia and intensive care unit department, Faculty of Medicine, Minia University Hospital, Minia, Egypt. E-mail: ahmedhassanein10@yahoo.com

Abeer Ahmed Mohamed Hassanein, MD, assistance professor in Anesthesia and intensive care unit department, Faculty of Medicine, Minia University Hospital, Minia, Egypt. Phone numbers: 01004234010. E-mail: abeerhassanine@yahoo.com

Corresponding contributor: Haidy Salah Mansour, MD, assistance professor in Anesthesia and intensive care unit department, Faculty of Medicine, Minia University Hospital, Minia, Egypt. Phone numbers: 01221802324. E- mail: haidy_mourad@yahoo.com

\begin{abstract}
Background: Peripheral nerve block has gained increased popularity due to less postoperative pain, reduced need for postoperative analgesic drugs, reduction of PACU time, and improved patient satisfaction. The aim of the study was to compare the effect of ketamine and dexmedetomidine on the supraclavicular nerve block.

Methods: 75 adult patients undergoing elective operations of the elbow, forearm, wrist, or hand were randomly allocated into three groups of 25 patients each. Group K (ketamine group) received $40 \mathrm{ml} 0.25 \%$ bupivacaine contain $1 \mathrm{mg} / \mathrm{kg}$ ketamine, Group D (dexmedetomidine group) received $40 \mathrm{ml} 0.25 \%$ bupivacaine contain $1 \mathrm{ug} / \mathrm{kg}$ dexmedetomidine, group $\mathrm{C}$ (control group) received $40 \mathrm{ml} 0.25 \%$ bupivacaine. The outcome measures included visual analog scale (VAS, $0=$ no pain $10 \mathrm{~cm}=$ the most severe pain), time to first analgesic request, and total dose of diclofenac analgesia given postoperatively. Sedation score also recorded in all groups
\end{abstract}

Results: Patients in D and K groups had reduced VAS scores than the C group, at alltime points after surgery during the first 24 hours, with more reduction in D than $\mathrm{K}$ group $(\mathrm{P}<0.05)$. The time of the first analgesic request in the $\mathrm{D}$ group was significantly more than in the $\mathrm{K}$ group and both were more than the $\mathrm{C}$ group $(9.48 \pm 1.417 \mathrm{~h}, 7.08 \pm 1.255 \mathrm{~h}$, and $5.00 \pm 1.04 \mathrm{~h}$ respectively).

Conclusions: The addition of ketamine or dexmedetomidine in the ultrasound-guided supraclavicular brachial plexus block could improve the postoperative pain and need for analgesia. Therefore, we can consider the low price more available ketamine as a comparable adjuvant in brachial plexus block to some extent as dexmedetomidine.

Trial registration: This trial was registered at (Clinicaltrials.gov): NCT04508894.

The date of registration: $(11 / 08 / 2020)$ 
Keywords: ketamine, dexmedetomidine, supraclavicular brachial plexus block, anesthesia.

\section{Introduction}

The supraclavicular brachial plexus block is a common anesthetic approach for upper limb surgery [1,2]. Ultrasound widely used to minimize the complications of the procedure [3]; many trials have been made to enhance the anesthetic and analgesic effects of the block by adding various adjuncts to the anesthetic agent. Drugs such as opioids, [4] clonidine [5], naloxone [6], midazolam [7]. Dexmedetomidine [5] epinephrine [8], have been added to the local anesthetics for this purpose with varying degrees of success. Dexmedetomidine is an imidazole compound that displays specific and selective $\alpha 2$-adrenoceptor agonist, enhances central and peripheral neural blockade by local anesthetics [9], however, the peripheral neural blockade is due to its binding to $\alpha 2 \mathrm{~A}-\mathrm{AR}$ [10]. Dexmedetomidine has been successfully used in brachial plexus block [11]. Ketamine is a noncompetitive blocker of the N-methyl-D aspartate (NMDA) receptor it is used for premedication, sedation, induction, and maintenance of general anesthesia [12]. It has shown that adding ketamine to epidural bupivacaine or lidocaine could increase the duration of regional anesthesia and postoperative analgesia [13]. This effect can be mediated by interaction with a number of receptors like (NMDA) receptors, opioids and muscarinic receptors $[14,15]$. In this present prospective double blind, randomized controlled study, we decide to compare the effects of $1 \mathrm{ug} / \mathrm{kg}$ dexmedetomidine and $1 \mathrm{mg} / \mathrm{kg}$ ketamine as adjuvants when added to local anesthetic in supraclavicular ultrasound guided block, Because adding ketamine to local anesthetics in brachial plexus block is still controversy, and also the studies that examined the effects of dexmedetomidine as adjuvants in nerve blocks is much more than that of ketamine, in spite of low price and more availability of ketamine in our country than dexmedetomidine.

The aim of the study was to compare the effect of ketamine and dexmedetomidine as additives to bupivacaine on onset and duration of the block, post-operative VAS, and analgesic consumption, after ultrasoundguided supraclavicular nerve block. 


\section{Patients and methods}

Ethical approval of the study protocol: The study approval and all experiments were performed in accordance with relevant guidelines and regulations of faculty of medicine, Minia university, research ethics committee (FMREC), (approval number: 146:4/2019).

This trial was registered at (Clinicaltrials.gov): NCT04508894.

The date of registration: (11/08/ 2020)

Patient recruitment: This double-blind randomized controlled was conducted on 75 patients in El-Minia university hospital. Informed consent was obtained from each patient; this study was conducted from April 2019 to July 2020 of Minia university hospital. Inclusion criteria were adults, of both sexes, aged 18-75 years, American Society of Anesthesiologists (ASA) physical status I-II, undergo elective and emergency (forearm and hand) surgeries under ultrasound guided supraclavicular brachial plexus block. Moreover, the exclusion criteria were any patient with bleeding disorders, damage or disease of the brachial plexus, uncontrolled diabetes mellitus, and patients with neuromuscular diseases, Patients with local skin infection at the site of injection or patients with known hypersensitivity to studied drugs

Preoperative assessment and preparation: A careful assessment of medical history, general examination including chest, heart, abdomen, site of injection and other systems were carried out. Routine investigations were done as complete blood picture, ECG (electrocardiogram) renal and liver functions. Explanation of visual analogue scale was done to each patient.

Preparation of the studied medications: The patients were randomly classified into three groups using computer generated table numbers each contain (25) patient. Ketamine group (group K) :20 ml 0.5\%bupivacaine and $20 \mathrm{ml} \mathrm{0.9 \%} \mathrm{normal} \mathrm{saline} \mathrm{plus} 1 \mathrm{mg} \backslash \mathrm{kg}$ ketamine, Dexmedetomidine group (group D) $20 \mathrm{ml} 0.5 \%$ bupivacaine and $20 \mathrm{ml} 0.9 \%$ normal saline plus $1 \mu \mathrm{g} \backslash \mathrm{kg}$ dexmedetomidine (precedex ${ }^{\circledR}$ Hospira,Inc.,Lake Forest USA).

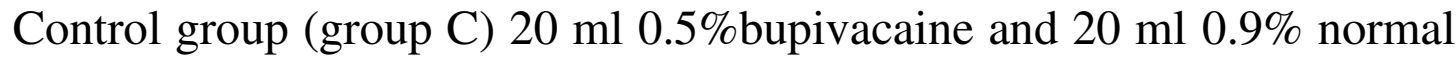
saline. In this study, the clinical investigator, the data analyst, and 
participant were all blinded to the study grouping. All medications were prepared in similar sterile coated bottles by the supervisor who did not included in anesthetic or operative team, 75 bottles numbered from 1 to 75 were prepared. After completion of the study, the key was opened by the supervisor

Block technique: On patient's arrival to the operating room, a $20 \mathrm{G}$ intravenous cannula was inserted in a peripheral vein of unaffected limb and standard monitoring commenced as noninvasive blood pressure (NIBP), (ECG), and Oxygen saturation (Spo2) (UltraviewSL2700,Spacelaps,USA), all equipment and drugs for general anesthesia and resuscitation were prepared, the ultrasound device (Sonosite, Nanomax ,USA ) lubricating gel, 21 guge $50 \mathrm{~mm}$ length, short bevel, insulated stimulating needle (Laboratoires pharmaceutiques, ygon, France). Patients lie supine with head turned to the other side and ipsilateral arm adducted gently with flexed elbow. Under complete aseptic condition, the identified area and the ultrasound probe was prepared with anti-septic (Povidone-Iodine 10\%) solution and the skin infiltrated with 1-2 $\mathrm{ml}$ of lidocaine $2 \%$ solution subcutaneously, the brachial plexus was visualized by placing the transducer in the sagittal plane in the supraclavicular fossa behind the middle-third of the clavicle. Two distinct appearances of the supraclavicular brachial plexus was seen, it either appeared as a grape like cluster of 5 to 6 hypoechoic circles, located lateral and superior to the subclavian artery between the anterior and middle scalene muscles at the lower cervical region or as 3 hypoechoic circles with hyperechoic outer rings, the predetermined volume of $40 \mathrm{~mL}$ of the study drug solution was administered around the brachial plexus after negative aspiration to avoid accidental intravascular injection, expansion of the brachial plexus sheath was considered as an indication of correct needle placement, multiple injections was used to deposit the total amount of the study drugs, skin massage for about 3 minutes was done to facilitate drug distribution.

\section{Parameters assessed:}

- Hemodynamic data: The hemodynamic variables as HR, MAP and Spo2 were assessed. The parameters were recorded preoperatively just before the block as a baseline value, at 5,10,20,30,60, 90 minutes during the operative time and at 1,2,4,6,9 and 12 hours after the end of operation. 
- Sensory block was assessed by pin prick test using a 3-point scale [16] Grade $0=$ normal sensation, Grade $1=$ loss of sensation of pin prick (analgesia), and Grade $2=$ loss of sensation of touch (anesthesia).

- Motor block was determined by thumb abduction (radial nerve), thumb adduction (ulnar nerve), thumb opposition (median nerve), and flexion of elbow (musculocutaneous nerve) according to the modified Bromage 3-point scale Grade 0: Normal motor function with full flexion and extension of elbow, wrist, and fingers. Grade 1: Decreased motor strength with ability to move the fingers only. Grade 2: Complete motor block with inability to move the fingers [16].

- Onset time for sensory and motor block: the time interval between the end of local anesthetic administration and complete sensory and motor block by min.

- Sensory block duration: the time interval between the complete sensory block and complete resolution of anesthesia on all the nerves (score 0)

- Motor block duration: the time interval from complete motor block to complete recovery of motor function of hand and forearm (grade 0 ) by hours.

- Visual analogue scale (VAS): postoperative, the patients were familiarized with a 10-point visual analog scale (VAS) ranged from 0 $=$ no pain, up to $10=$ the worse imaginable pain. VAS was measured at $1,2,3,6,9,12$ hours. When it is equals or $>4$ we give IM diclofenac sodium (75 mg amp) (voltaren, Novartis Pharmaceuticals Corporation, Switzerland).

- Time of first analgesic request: The time passed from supraclavicular brachial plexus block to the patient's first request for analgesic medication by hours

- Total analgesic requirements in 24 hours (diclofenac consumption)

- Sedation score: was assessed according to the modified Ramsay Sedation Scale 1987(RSS) from 1-6 as follows: 1 = anxious, agitated, restless; $2=$ cooperative, oriented, tranquil; $3=$ responds to commands only; $4=$ brisk response to light glabellar tap or loud noise; $5=$ sluggish response to light glabellar tap or loud noise; $6=$ no response [17].

- Adverse effects: any adverse effects such as hypotension (i.e. 20\% decrease relative to baseline), bradycardia (HR $<60$ beats/min), 
nausea, vomiting, hypoxemia ( $\mathrm{SpO} 2<90 \%)$, local hematoma, hemothorax, pneumothorax, recurrent laryngeal nerve block, intravascular injection, Horner's syndrome and signs of local

anesthetic toxicity were recorded during the operation and for 12 hours postoperative.

\section{Outcome}

The duration of sensory block was considered as primary outcome. The secondary outcomes were evaluating the onset of sensory and motor block, postoperative pain score, time to first analgesic request, total analgesic requirements, and sedation score.

\section{Sample size and Statistical analysis}

Results were calculated as mean \pm standard deviation (SD) and MannWhitney test for quantitative variables, categorical variables were calculated using Chi- square test or Fisher's exact test Statistical significance was determined when $P \leq 0.05$. All statistical analysis was done using SPSS software (version 13.0, SPSS Inc., Chicago, Illinois). To determine the sample size, we used sample size calculator for comparing two independent means [18]. It was calculated regarding the onset of analgesia using local anesthetics for supraclavicular nerve block, which was determined in previous studies [19]. Assuming a pooled standard deviation of 12 minutes and expected mean difference of 10 minutes between test and reference groups, the study would require a sample size of 23 patients for each group, with a power of $80 \%$ - and twosided level of significance of 5\%, at a confidence interval (CI) of $95 \%$. Therefore, a sample of 25 patients in each group could be sufficient to achieve the targeted onset of analgesia. 


\section{Results:}

From April 2019 to July 2020, 92 patients were enrolled, 75 of whom completed the study. Seven patients not meeting inclusion criteria and ten patients refused to participate (Fig. 1).

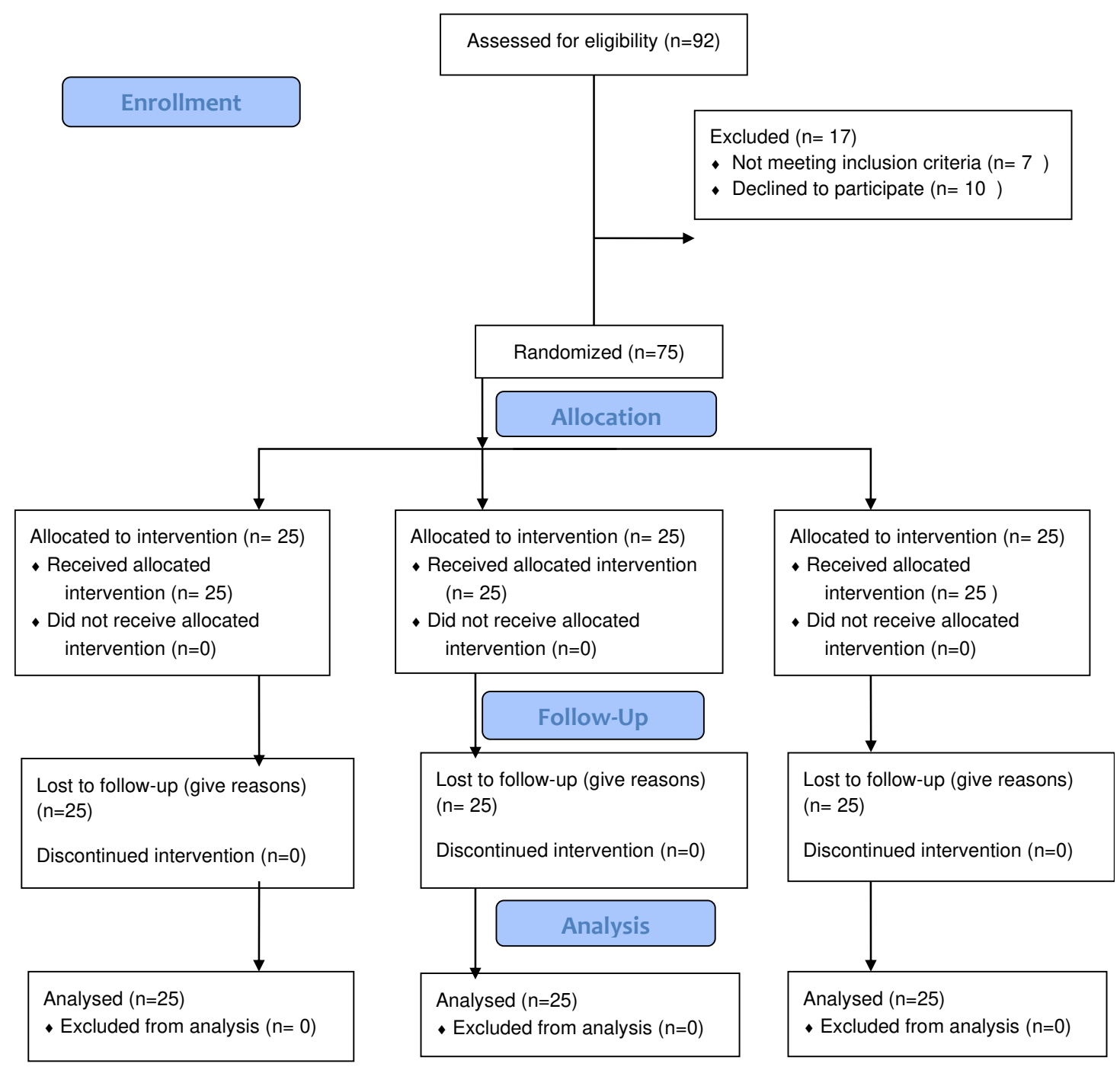

Figure 1: CONSORT diagram showing the flow of participants 
Patients demographic data including age, sex, weight, operative time, and ASA physical status were not significantly different between the three study groups (Table 1).

Table 1: Patient characteristics

\begin{tabular}{|c|c|c|c|c|c|c|}
\hline Variable & $\begin{array}{l}\text { Group k } \\
(\mathrm{n}=25)\end{array}$ & $\begin{array}{l}\text { Group D } \\
(\mathrm{n}=25)\end{array}$ & $\begin{array}{l}\text { Group C } \\
(n=25)\end{array}$ & K vs D & K vs C & D vs C \\
\hline Age (years) & $\begin{array}{l}18-75 \\
49.16 \pm 16.17\end{array}$ & $\begin{array}{l}20-68 \\
47.84 \pm 13.11 \\
\end{array}$ & $\begin{array}{l}19-74 \\
46.2 \pm 17.6\end{array}$ & 0.95 & 0.79 & 0.93 \\
\hline Gender (M/F) & $11 / 14$ & $12 / 13$ & $11 / 14$ & 0.77 & 1 & 0.77 \\
\hline Weight (kg) & $\begin{array}{l}60-80 \\
71.56 \pm 5.48\end{array}$ & $\begin{array}{l}60-80 \\
71.60 \pm 6.14 \\
\end{array}$ & $\begin{array}{l}61-79 \\
69.2 \pm 5.55\end{array}$ & 1 & 0.33 & 0.31 \\
\hline $\begin{array}{l}\text { Operative } \\
\text { time (min) }\end{array}$ & $\begin{array}{l}70-90 \\
79.16 \pm 6.67\end{array}$ & $\begin{array}{l}68-91 \\
80.32 \pm 7.86\end{array}$ & $\begin{array}{l}70-89 \\
80.6 \pm 5.54\end{array}$ & 0.07 & 0.40 & 0.44 \\
\hline ASA (I/II) & $16 / 9$ & $14 / 11$ & $17 / 8$ & 0.56 & 0.76 & 0.38 \\
\hline
\end{tabular}

The statistical analysis did not show any significant differences between the three groups regarding (HR) or(MAP) when they were recorded at (baseline), at 5,10,20,30,60,90 minute intraoperative, and at $1 \mathrm{~h}, 2 \mathrm{~h}, 4 \mathrm{~h}$, $6 \mathrm{~h}, 9 \mathrm{~h}$, and $12 \mathrm{~h}$ postoperative, in spite of the decrease of MAP in the D group at $20 \mathrm{~min}$ intraoperative till $1 \mathrm{~h}$ postoperative, p-values for HR , and MAP when calculated between ( $\mathrm{K}$ and $\mathrm{D}$ groups) or ( $\mathrm{K}$ and $\mathrm{C}$ groups) or (D and C groups) showed no statistically significance ( $p$ value $>0.05$ ) (figure $2 \& 3$ ). 


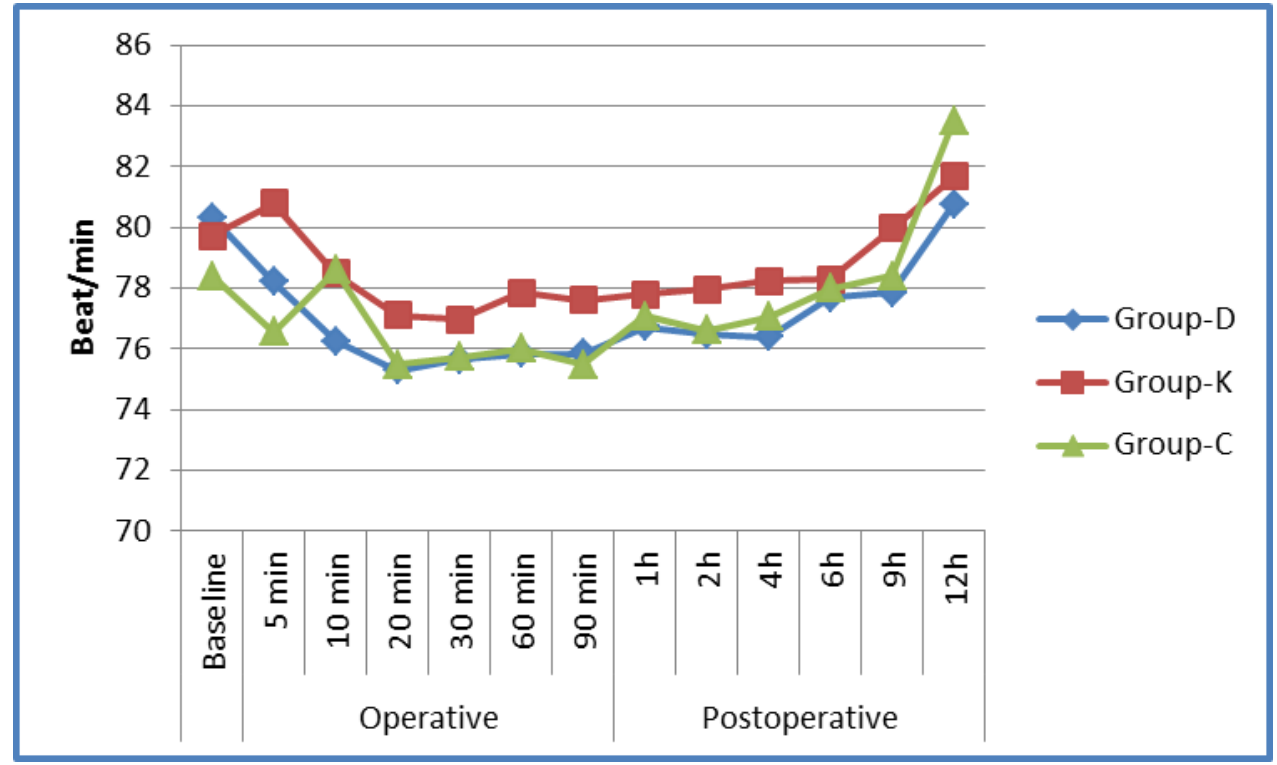

Figure 2: Heart rate changes in the study groups

K:ketamine. D : dexmedetomidine. C : control.min: minute. h: hour

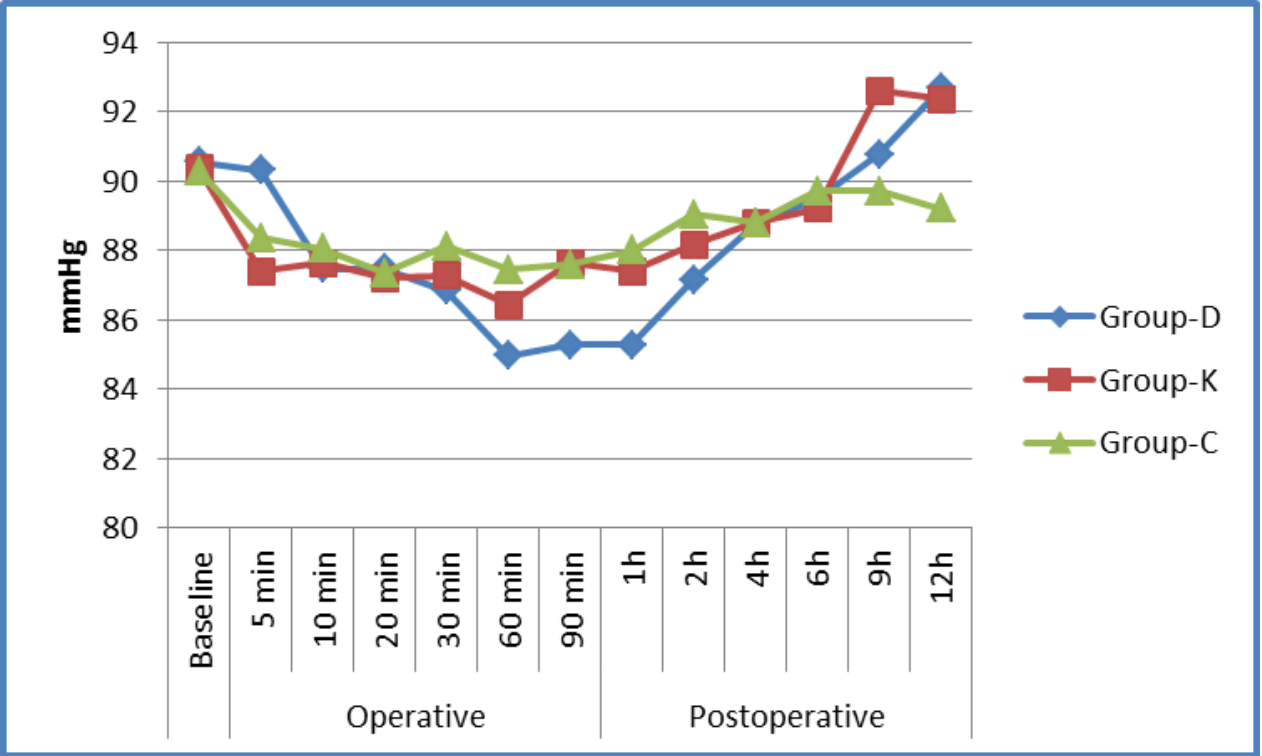

Figure 3: Mean arterial pressure changes in the study groups ketamine. D: dexmedetomidine. C: control. h: hour. min: minute

Regarding onset of sensory block, D group were rapid onset than $\mathrm{K}$ and C groups $(11.52 \pm 1.686 \mathrm{~min}, 13.32 \pm .988 \mathrm{~min}$ and $13.60 \pm 1.190 \mathrm{~min}$ respectively), with significant difference between $\mathrm{D}$ and $\mathrm{K}, \mathrm{D}$ and $\mathrm{C}$ groups, and non-significant difference between $\mathrm{K}$ and $\mathrm{C}$ groups. The onset of motor block were rapid in the $\mathrm{D}$ group than $\mathrm{K}$ and $\mathrm{C}$ groups (13.56 $\pm 1.474 \mathrm{~min}, 16.28 \pm 3.089 \mathrm{~min}$ and $17.76 \pm 1.665 \mathrm{~min}$ respectively) with significant difference between $\mathrm{D}$ and $\mathrm{K}, \mathrm{D}$ and $\mathrm{C}$ groups ( $\mathrm{p}$ value 
$<0.05$ ), and non-significant difference between $\mathrm{K}$ and $\mathrm{C}$ groups ( $P$ value $>0.05$ )( figure $5 \&$ table 2). Duration of sensory and motor block was longer in group D $(11.72 \pm 1.173$ and $11.52 \pm 1.122$ hour $)$ than group $\mathrm{K}$ (9.80 \pm 1.190 and $9.04 \pm 1.306$ hour) and group $C(7.76 \pm .925$ and 6.80 \pm .707 hour) respectively, with significant difference in between the three groups ( $P$ value $=0.0001$ ) (figure $4 \&$ table 2 ). Time of administration of the first dose of diclofenac was significantly more in the $\mathrm{D}$ group than $\mathrm{K}$ and $\mathrm{C}$ groups respectively, but the total diclofenac dose was less in $\mathrm{D}$ and become more in $\mathrm{K}$ group and much more in $\mathrm{C}$ group, $\mathrm{p}$ value $<0.05$. ( table 3)

Table 2: Block Characteristics : sensory and motor onset and duration.

\begin{tabular}{|l|l|l|l|l|l|l|}
\hline Variables & K & D & \multicolumn{2}{l|}{ C } & \multicolumn{2}{l|}{ P Value } \\
\cline { 2 - 7 } & Mean \pm SD & Mean \pm SD & Mean \pm SD & K vs D & K vs C & D vs C \\
\hline $\begin{array}{l}\text { Sensory_onset } \\
\text { (min) }\end{array}$ & $13.32 \pm .988$ & $11.52 \pm 1.686$ & $13.60 \pm 1.190$ & .0001 & .735 & .0001 \\
\hline $\begin{array}{l}\text { Motor_onset } \\
\text { (min) }\end{array}$ & $16.28 \pm 3.089$ & $13.56 \pm 1.474$ & $17.76 \pm 1.665$ & .0001 & .051 & .0001 \\
\hline $\begin{array}{l}\text { Sensory_duration } \\
\text { (h) }\end{array}$ & $9.80 \pm 1.190$ & $11.72 \pm 1.173$ & $7.76 \pm .925$ & .0001 & .0001 & .0001 \\
\hline $\begin{array}{l}\text { Motor_Duration } \\
\text { (h) }\end{array}$ & $9.04 \pm 1.306$ & $11.52 \pm 1.122$ & $6.80 \pm .707$ & .0001 & .0001 & .0001 \\
\hline
\end{tabular}

Data are expressed as mean \pm standard deviation. $S D$ : standard deviation. $K$ :ketamine. $D$ : dexmedetomidine. $c$ : control. $h$ : hour 


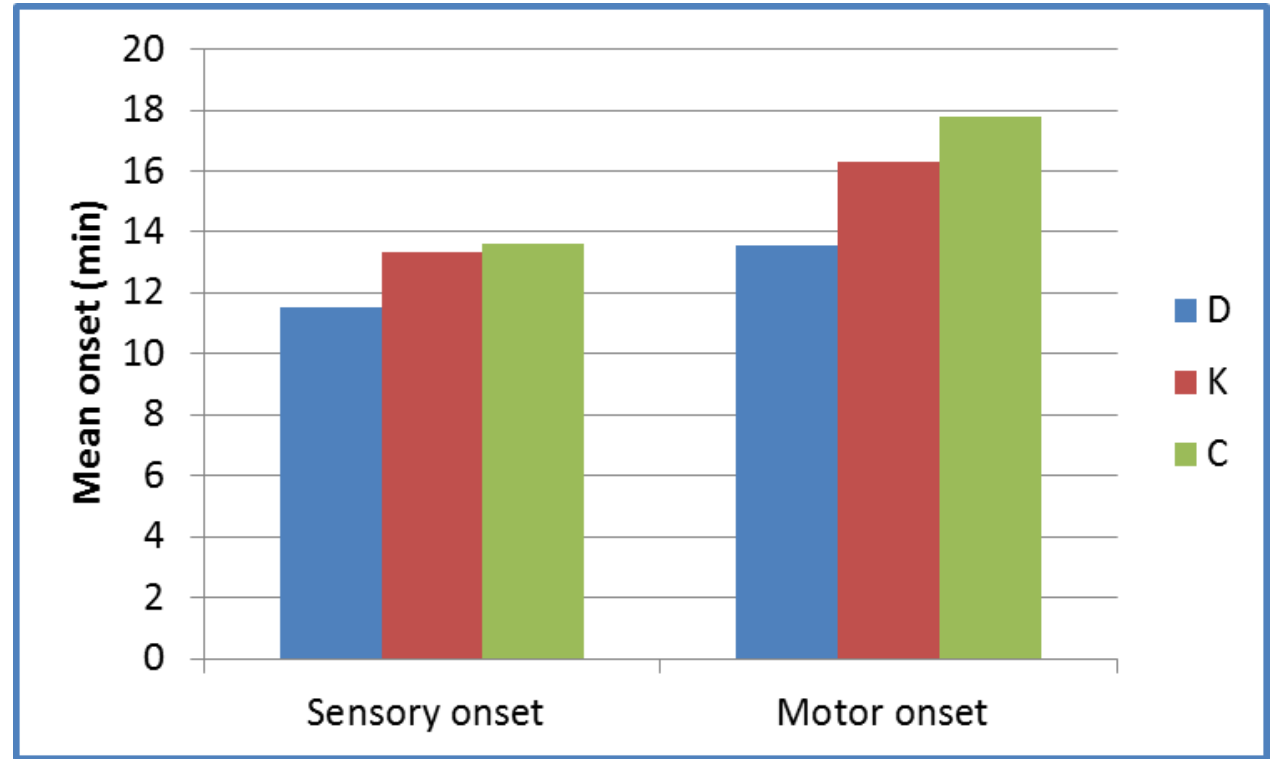

Figure 4: mean time to sensory and motor block onset in the study groups. $\mathrm{K}$ :ketamine. $\mathrm{D}$ : dexmedetomidine. $\mathrm{C}$ : control

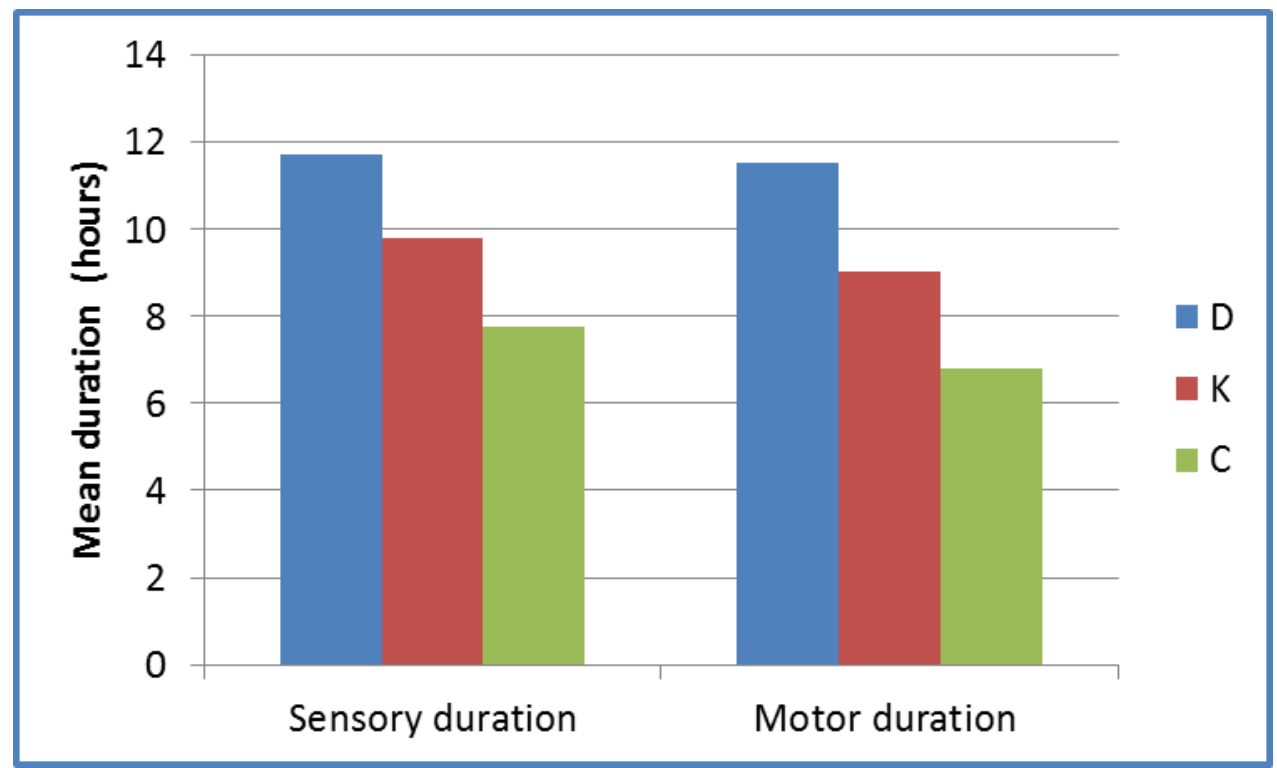

Figure 5: mean sensory and motor block duration in the study groups. $\mathrm{K}$ :ketamine. $\mathrm{D}$ : dexmedetomidine. $\mathrm{C}$ : control 
Table 3: Mean time to first analgesic request (hour) and diclofenac consumption (mg)

\begin{tabular}{|l|l|l|l|l|l|l|}
\hline & $\mathrm{K}$ & $\mathrm{D}$ & $\mathrm{C}$ & \multicolumn{3}{|l|}{ P Value } \\
\cline { 2 - 8 } & Mean \pm SD & Mean \pm SD & Mean & K vs D & K vs C & D vs C \\
\hline $\begin{array}{l}\text { First_analgesic_request } \\
\text { (h) }\end{array}$ & $7.08 \pm 1.255$ & $9.48 \pm 1.417$ & $5.00 \pm 1.04$ & .0001 & .0001 & .0001 \\
\hline $\begin{array}{l}\text { Diclofenac consumption } \\
\text { (mg) }\end{array}$ & $\begin{array}{l}171.00 \pm 34.3 \\
69\end{array}$ & $105.00 \pm 37.50$ & $\begin{array}{l}213.00 \\
28.062\end{array}$ & .0001 & .0001 & .0001 \\
& & & & & & \\
\hline
\end{tabular}

Data are expressed as mean \pm standard deviation. SD : standard deviation. $K$ :ketamine. $D$ : dexmedetomidine.

C: control. h: hour.

After the first hour postoperative, VAS readings were significantly lower in $\mathrm{D}$ and $\mathrm{K}$ groups when compared to $\mathrm{C}$ groups ( $\mathrm{p}<0.05$ ), the readings in $\mathrm{K}$ group were significantly higher than $\mathrm{D}$ group $(\mathrm{p}<0.05)$ except at $2 \mathrm{~h}$ and $9 \mathrm{~h}$ points, the difference was not significant ( $\mathrm{p}>0.05$ ) (figure 6 ).

Sedation score recorded after performing the block at $10 \mathrm{~min}, 30 \mathrm{~min}, 1 \mathrm{~h}$, $3 \mathrm{~h}$, $6 \mathrm{~h}$, and showed significant high reading in $\mathrm{D}$ group than $\mathrm{K}$ and $\mathrm{C}$ groups at all readings ( $\mathrm{p}<0.05)$, also the $\mathrm{K}$ group were significantly higher than $\mathrm{C}$ group ( $\mathrm{p}<0.05$ ) except at $10 \mathrm{~min}$ and $6 \mathrm{~h}$ time points the score was not significant statistically ( $p>0.05$ ) (figure 7). Adverse effects occurred in 5 patients (1 patient had nausea and vomiting, 2 patient had agitation, and 2 patients had injection site ecchymosis) in the $\mathrm{K}$ group and 4 patients ( 2 patients had nausea and vomiting, 1 patient had agitation, and 1 patient had injection site ecchymosis) in the D group and 5 patients ( 2 patients had nausea and vomiting, 1 patient had agitation, and 2 patient had injection site ecchymosis) in the $\mathrm{C}$ group. There were no significant differences among the three groups in the incidence of adverse effects. 


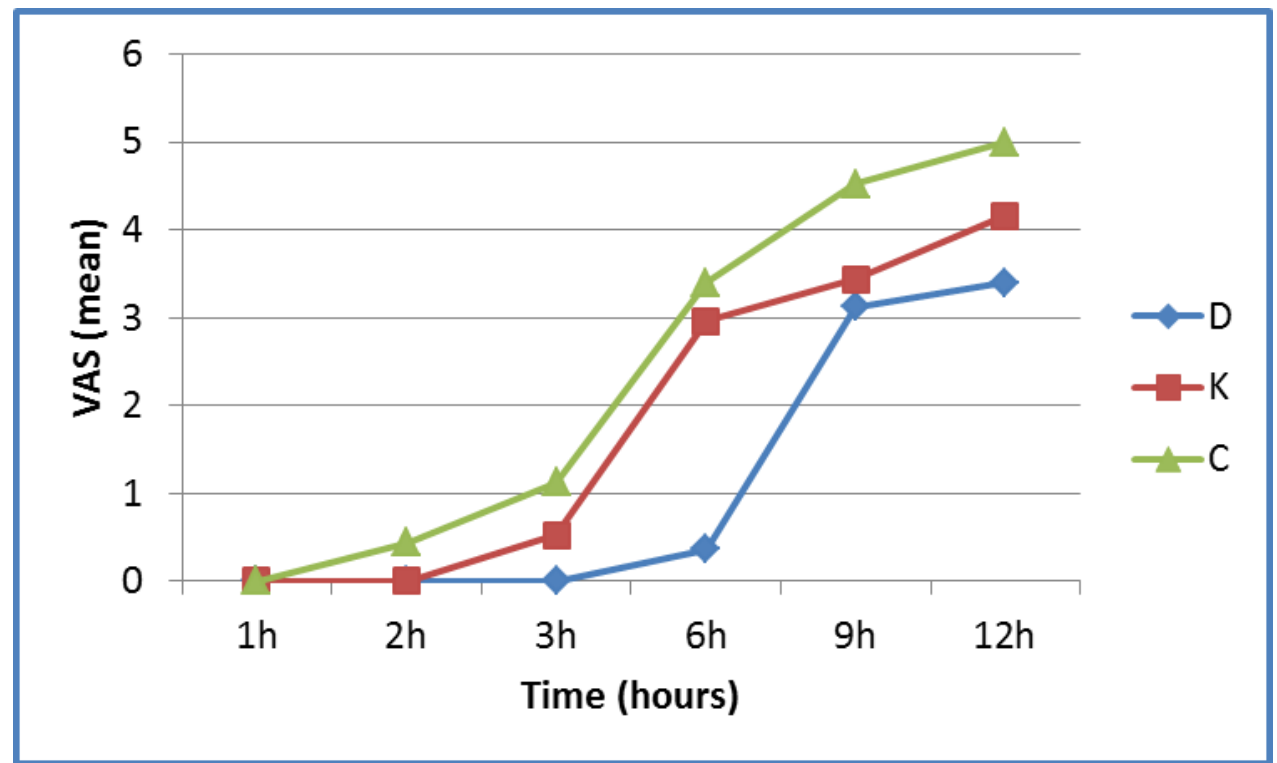

Figure 6: mean post-operative VAS in the study groups.

VAS : visual analogue scale. K: ketamine. D : dexmedetomidine. C : control

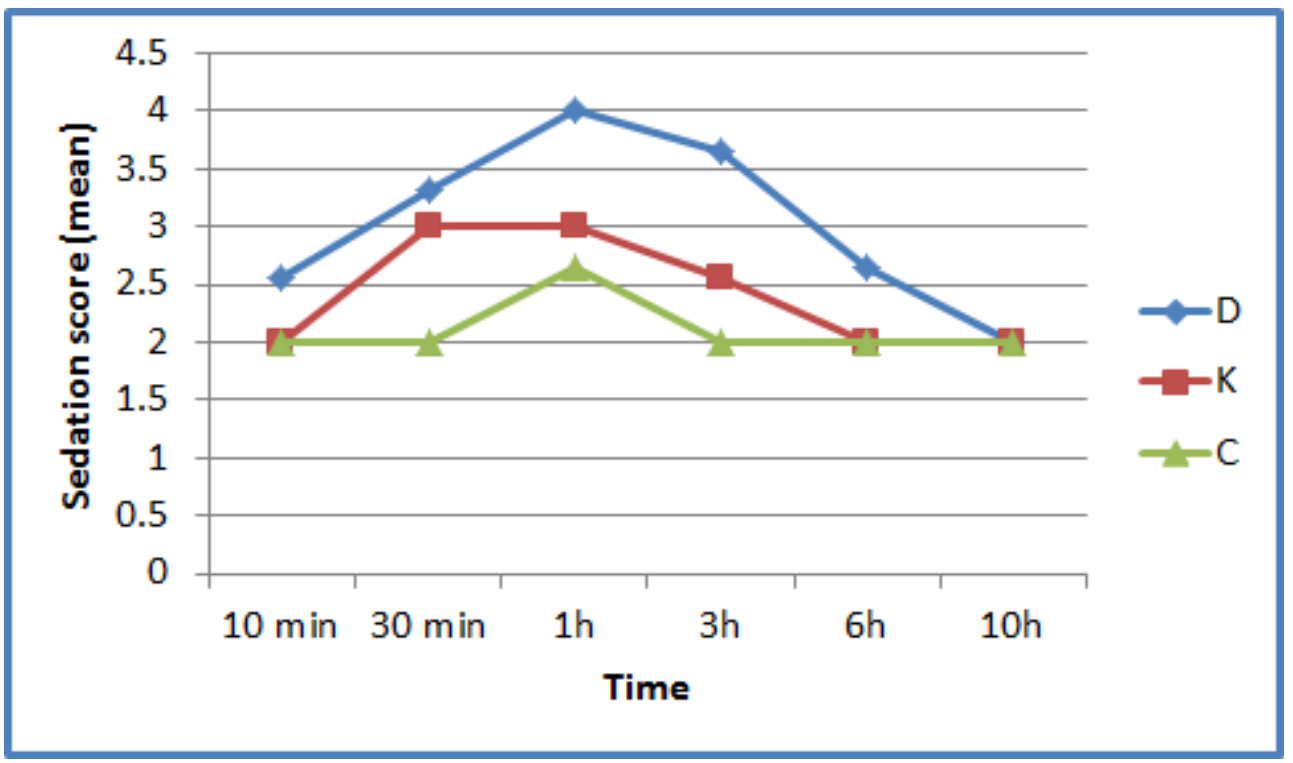

Figure 7: mean sedation score in the study groups.

$\mathrm{K}$ :ketamine. $\quad \mathrm{D}$ : dexmedetomidine. $\quad \mathrm{C}$ : control h: hour

\section{Discussion}

Dynamic visualization of the anatomical structures and placement of the needle along with observation of injectate spread in real time become the main advantages of ultrasound-guided regional anesthesia (UGRA). Randomized controlled trials for long-term complications such as nerve injury and systemic toxicity of local anesthetics still defective regarding UGRA, although a prospective study of 12668 UGRA blocks 
over 8 years recorded only one case of intravascular injection of local anesthetic and seizure [20]. This demonstrates the relative safety of UGRA block. The brachial plexus block is carried out by injecting local analgesics in the fascial planes around the nerve plexus, resulting in block the sensory, motor, and autonomic fibers supplying the upper extremity. It is safe, simple, and effective method of anesthesia and analgesia with many advantages over general and intravenous regional anesthesia especially in patients with poor general condition as uncontrolled diabetes, respiratory or cardiovascular diseases, also, in patients they prefer to retain their consciousness during surgery [21].

Dexmedetomidine is a highly selective $\alpha 2$ adrenoceptor agonist [22]. With presynaptic activation of $\alpha 2$ adrenoceptor in central nervous system (CNS), it can inhibit release of norepinephrine and prevent pain signals propagation with inhibition of sympathetic outflow, resulting in attenuation of HR and BP [23].

Ketamine is a phencyclidine derivative that has many central effects through the $\mathrm{N}$-methyl-D-aspartate receptor (NMDA). It is used for premedication, sedation, induction, and maintenance of general anesthesia. IV administration of ketamine provides postoperative analgesia through its central mechanism [15] The sub-anesthetic dose of ketamine may act as an anti-hyperalgesic or antiallodynic agent has gained interest in pain management [24, 25]. Dowdy et al., [26] demonstrated the local anesthetic properties of ketamine that could produce reversible suppression of the compound action potential in the stimulated sciatic nerve in frog. Also, ketamine injection produces reversible segmental paralysis in dogs (without alteration of the conscious level). This effect of ketamine on nerve conduction was demonstrated by Weber et al., [27] who reported that the subcutaneous injection of ketamine causing loss of pain and thermal sensations fort 8-10 minutes. In our study the ketamine $1 \mathrm{mg} / \mathrm{kg}$ when added to bupivacaine for ultrasound guided supraclavicular brachial plexus block showed shortening the onset of motor and sensory block, prolong the duration of analgesia postoperative and reduce the amount of analgesic rescue, these effects when compared with control group. When we compare these ketamine adjuvant effects with another adjuvant dexmedetomidine, our results showed more rapid sensory and motor onset, more prolonged 
sensory and motor block, also with less amount of diclofenac analgesic needed in group D than group $\mathrm{K}$. there was hemodynamic stability among the 3 groups in spit non-significant decrease in MAP and HR in D group that can be explained by systemic effect of sympathoplegic dexmedetomidine. No difference regarding incidence of the side effects among the 3 studied groups.

In agreement with our study, Mostafa et a 2014,[28] They was studied Sixty ASA I and II patients allocated for elective upper limb surgeries by supraclavicular block were divided into two equal groups in a randomized, double-blinded way. Group D received $1 \mu \mathrm{g} / \mathrm{kg}$ dexmedetomidine and group $\mathrm{K}$ received $2 \mathrm{mg} / \mathrm{kg}$ Ketamine added to bupivacaine $0.25 \%(25 \mathrm{cc})$. There was no statistically significant difference regarding the onset of sensory and motor block. Duration of sensory and motor block was $413.97 \pm 87.13$ and $472.24 \pm 90.06 \mathrm{~min}$, in group D. while it was $227.00 \pm 48.36$ and $292.67 \pm 59.13 \mathrm{~min}$, in group K. The time to first analgesic requisite in group D $(456 \pm 97 \mathrm{~min})$, while in group K $(289 \pm 62 \mathrm{~min})$.

The study of Esmaoglu et al., 2010. dexmedetomidine added to levobupivacaine in Axillary Block, showed that onset of Sensory and motor block was statistically significant shorter in LD group (levobupivacaine+ Dexmedetomidine) than in L group (levobupivacaine) [11], also, Agarwal et al., 2014 they examine the effect of adding $1 \mu \mathrm{g} / \mathrm{kg}$ dexmedetomidine to $30 \mathrm{ml}$ bupivacaine $0.325 \%$ using the supraclavicular brachial plexus block for forearm operations. They compared it to a control group (bupivacaine $0.325 \%$ ), they conclude that the addition of $1 \mu \mathrm{g} / \mathrm{kg}$ of dexmedetomidine ware fasting the sensory and motor onset, effectively and significantly prolongs the motor and sensory duration, prolong analgesia time [17] .

Also, Lashgarinia, et al., studied sixty adult patients undergoing elective operations in elbow, forearm, wrist or hand were randomly allocated in 2 equal groups. G1 (ketamine group) received $5 \mathrm{mg} / \mathrm{kg}$ lidocaine $1.5 \%$ mixed with $2 \mathrm{mg} / \mathrm{kg}$ ketamine, G 2 (control group) received $5 \mathrm{mg} / \mathrm{kg}$ lidocaine $1.5 \%$ only. Higher VAS recorded in control than ketamine group, at all-time points during the first 24 hours postoperative $(\mathrm{P}<$ 0.05). The time to first analgesic request in the ketamine group was 
significantly higher than that in control group $(8.93 \pm 1.0 \mathrm{~h}$ vs. $7.30 \pm 1.9$ h) $(\mathrm{P}<0.001)$ [29]

In contrary to our results, Rahimzadeh et al. studied the analgesic effects of peri-femoral nerve infusion of ropivacaine plus ketamine versus ropivacaine, alone after elective repairing the ACL, using spinal anesthesia. They reported that ketamine $1 \mathrm{mg} / \mathrm{kg}$ with $0.1 \%$ ropivacaine could not control postoperative pain in the post-operative period [30]. Also, (cleric, et al. 2005) examined the analgesic effects of wound infiltration and inguinal field block with either $30 \mathrm{~mL}$ bupivacaine $(0.5 \%)$ or with the same volume of a mixture of $27 \mathrm{~mL}$ bupivacaine $(0.5 \%)+3 \mathrm{~mL}$ ketamine $(75 \mathrm{mg})$ or a $28 \mathrm{~mL}$ bupivacaine $(0.5 \%)+2 \mathrm{~mL}$ ketorolac $(60 \mathrm{mg})$. The results were comparable in the 3 groups, highest VAS at 24 hours, which was significantly different from those at 6 and 48 hours $(\mathrm{P}<0.05)$. pain score was lower in ketorolac group at 24 and 48 hours and in ketamine group at 48 hours, there were no other differences in pain scores or amount of rescue analgesic in the 3 groups throughout the 48-hour. They concluded that he addition of ketamine or ketorolac improves very little the analgesic effect of bupivacaine infiltration after hernia repair [31].

The variations in ketamine effect in different studies probably came from the ketamine different concentrations and different anatomical sites of injection. We used $1 \mathrm{mg} / \mathrm{kg}$ to avoid large dose and its sedative or psychomotor effects, no major hemodynamic alterations in the 3 studied groups, and no major complications recorded.

Our opinion: the range of ketamine doses of $(1-2 \mathrm{mg} / \mathrm{kg})$ when used as adjuvant to local anesthetic in brachial plexus block, may became comparable to some extent to dexmedetomidine $(1 \mathrm{ug} / \mathrm{kg})$, this makes ketamine alternative adjuvant to expensive less frequently available dexmedetomidine We can do further studies using higher doses of ketamine as $1.5,2 \mathrm{mg} / \mathrm{kg}$, as sedation score still allowed and no annoying major side effects.

Limitations of our study including lack of data about the effects of these additives in patients of ASA 3 and 4, also lack of BSI value in monitoring of sedation effects of both drugs (ketamine and dexmedetomidine).

The results of the study can be generalized and applied to allow using of ketamine and dexmedetomidine as adjuvants to provide extensive blocks and reduce the rescue post-operative analgesic drugs. 
Finally, we can interpretates that both ketamine and dexmedetomidine can safely use in sonar guided brachial plexus slim blocks with nearly comparable analgesic and sedative effects in patients with ASA I and II.

\section{References:}

1. De Tran QH, Clemente A, Doan J, Finlayson RJ. Brachial plexus blocks: A review of approaches and techniques. Can J Anaesth. 2007;54:662-74

2. Mian A, Chaudhry I, Huang R, Rizk E, Tubbs RS, Loukas M. Brachial plexus anesthesia: A review of the relevant anatomy, complications, and anatomical variations. Clin Anat. 2014;27:210-21.

3. Kapral S, Krafft P, Eibenberger K, Fitzgerald R, Gosch M, Weinstabl

C. Ultrasound-guided supraclavicular approach for regional anesthesia of the brachial plexus. Anesth Analg. 1994;78:507-13.

4. Nishikawa K, Kanaya N, Nakayama M, Igarashi M, Tsunoda K, Namiki A. Fentanyl improves analgesia but prolongs the onset of axillary brachial plexus block by peripheral mechanism. Anesth Analg. 2000;91:384-7.

5. Swami SS, Keniya VM, Ladi SD, Rao R. Comparison of dexmedetomidine and clonidine ( $\alpha 2$ agonist drugs) as an adjuvant to local anaesthesia in supraclavicular brachial plexus block: A randomised double-blind prospective study. Indian J Anaesth. 2012;56:243-9.

6. Movafegh A, Nouralishahi B, Sadeghi M, Nabavian O. An ultra-low dose of naloxone added to lidocaine or lidocaine-fentanyl mixture prolongs axillary brachial plexus blockade. Anesth Analg. 2009;109:1679-83

7. Trivedi V, Patel N. A comparative clinical study of injection clonidine versus midazolam in supraclavicular brachial plexus block for sedation and postoperative analgesia: A study of 60 cases. J Indian Med Assoc. 2010;108:563-7

8. Chawda PM, Sharma G. A clinical study comparing epinephrine 200 $\mu \mathrm{g}$ or clonidine $90 \mu \mathrm{g}$ as adjuvants to local anaesthetic agent in brachial plexus block via supraclavicular approach. J Anaesthesiol Clin Pharmacol. 2010;26:523-7.

9. Kanazi, G., Aouad, M., Jabbour-Khoury, S., Al Jazzar, M. et al . Effect of low-dose dexmedetomidine or clonidine on the characteristics of 
bupivacaine spinal block. Acta anaesthesiologica scandinavica. 2006; 50, 222-227.

10.Yoshitomi, T., Kohjitani, A., Maeda, S., Higuchi, H. et al. Dexmedetomidine enhances the local anesthetic action of lidocaine via an $\alpha-2 \mathrm{~A}$ adrenoceptor. Anesthesia \& Analgesia. 2008; 107, 96-101

11..Esmaoglu A, Yegenoglu F, Akin A, Turk CY. Dexmedetomidine added to levobupivacaine prolongs axillary brachial plexus block. Anesthesia \& Analgesia. 2010; 111:1548-1551.

12. Haas DA, Harper DG. Ketamine: A review of its pharmacologic properties and use in ambulatory anesthesia. Anesth Prog. 1992;39:61-8. 13. Abdel-Ghaffar ME, Abdulatif M, al-Ghamdi A, Mowafi H, Anwar A. Epidural ketamine reduces postoperative epidural PCA consumption of fentanyl/bupivacaine. Can J Anaesth. 1998; 45:103-9.

14. Movafegh A, Razazian M, Hajimaohamadi F, Meysamie A. Dexamethasone added to lidocaine prolongs axillary brachial plexus blockade. Anesth Analg. 2006; 102: 263 -7.

15. Reves JG, Glass PS, Lubarsky DA, McEvoy MD, Martinez Ruiz R. Intravenous Anesthetics. In: Miller R, editor. Miller's Anesthesia. 7th ed. Orlando: Churchill Livingstone. 2009; p. 225.

16. Lee IO., Kim WK., Kong MH., et al.: "No enhancement of sensory and motor blockade by ketamine added to ropivacaine interscalene brachial plexus blockade." Acta anaesthesiologica scandinavica, 2002;46(7):821-826.

17. Agarwal, S., Aggarwal, R. \& Gupta, P.): Dexmedetomidine prolongs the effect of bupivacaine in supraclavicular brachial plexus block. Journal of Anaesthesiology Clinical Pharmacology. 2014; 30, 36.

18.Dhand NK, Khatkar MS: An online statistical calculator. Sample Size Calculator for Comparing Two Independent Means. Statulator (2014).

19. Lim HJ, Hasan MS, Chinna K. Faster onset time of supraclavicular brachial plexus block using local anesthetic diluted with dextrose. Brazilian Journal of Anesthesiology (English Edition). 2016 ;66(4): 341345 .

20. Sites BD, Taenzer AH, Herrick MD, Gilloon C. Incidence of local anesthetic systemic toxicity and postoperative neurologic symptoms associated with 12,668 ultrasound-guided nerve blocks: An analysis from a prospective clinical registry. Regional anesthesia and pain medicine. $2012 ; 37: 478-482$. 
21. Kumar S, Palaria U. and Sinha A. "Comparative evaluation of ropivacaine and ropivacaine with dexamethasone in supraclavicular brachial plexus block for postoperative analgesia." Anesthesia, Essays and Researches. 2014; 8(2):202.

22. Carollo D., Nossaman B and Ramadhyani U. dexmedetomidine: A review of clinical applications. Curr Opin Anaesthesiol. 2008:;21:45761.

23. Hall J., Uhrich T., Barney J., Arain S. and Ebert T. 2000: Sedative, amnestic, and analgesic properties of small-dose dexmedetomidine infusions. Anesth Analg. 2000; 90:699-705.

24. Visser E, Schug SA. The role of ketamine in pain management. Biomed Pharmacother. 2006; 60:341-8

25. Argiriadou H, Papagiannopoulou P, Foroulis CN, Anastasiadis K, Thomaidou E, Papakonstantinou $\mathrm{C}$, et al. Intraoperative infusion of $\mathrm{S}(+)$ ketamine enhances post-thoracotomy pain control compared with perioperative parecoxib when used in conjunction with thoracic paravertebral ropivacaine infusion. J Cardiothorac Vasc Anesth. 2011;25:455-61.

26. Dowdy EG, Kaya K, Gocho Y. Some pharmacologic similarities of ketamine, lidocaine, and procaine. Anesth Analg. 1973; 52:839-42

27. Weber WV, Jawalekar KS, Jawalekar SR. The effect of ketamine on nerve conduction in isolated sciatic nerves of the toad. Neurosci Lett. 1975;1:115-20.

28. Mostafa Mohamad Sabra, Badr Ismael Fadlallah, Abd Al-Wahab Saleh, Ali Alkomeyty and Hatem Alkenany. Dexmedetomidine versus ketamineas an adjuvant in ultrasound guided axillary bracheal plexus block. AAMJ. 2014; VOL, (12), NO (4), OCT. SUPLL.

29. Mohammadreza Lashgarinia, Khosro Naghibi, Azim Honarmand, Mohammadreza Safavi, and Mehdi Khazaei. Effect of ketamine as an adjuvant in ultrasound-guided supraclavicular brachial plexus block: A double-blind randomized clinical trial study. Adv Biomed Res. 2014; v.3; PMC4260270 .

30. Rahimzadeh P, Faiz SH, Ziyaeifard M, Niknam K. Effectivness of adding ketamine to ropivacaine infusion via femoral nerve catheter after knee anterior cruciate ligament repair. J Res Med Sci. 2013;18:632-6.

31. Clerc S, Vuilleumier H, Frascarolo P, Spahn DR, Gardaz JP. Is the effect of inguinal field block with $0.5 \%$ bupivacaine on postoperative 
pain after hernia repair enhanced by addition of ketorolac or $\mathrm{S}(+)$ ketamine? Clin J Pain. 2005;21:101-5.

Ethics approval, guidelines, and consent to participate: The written informed consent was obtained from patients. The study approval and all experiments were performed in accordance with relevant guidelines and regulations of faculty of medicine, Minia university, research ethics committee (FMREC).

Consent for publication: Not applicable.

Availability of data and materials: The data are available upon request to the corresponding author.

Authors' contributions: All authors read and approved the final manuscript. AHM performed study design and conduction, data collection and analysis, preparation of the manuscript, and writing up of the first draft. AAMH performed study design and conduction, data collection, and analysis. Authors' contributions HSM performed study design and conduction, data collection and analysis, and revising the manuscript.

Competing interests: The authors declare that they have no competing interests.

Funding This research received no specific grant from any funding agency in the public.

Acknowledgments: We thank all member of anesthesiology department, faculty of medicine. Minia University, Egypt. 
Figures

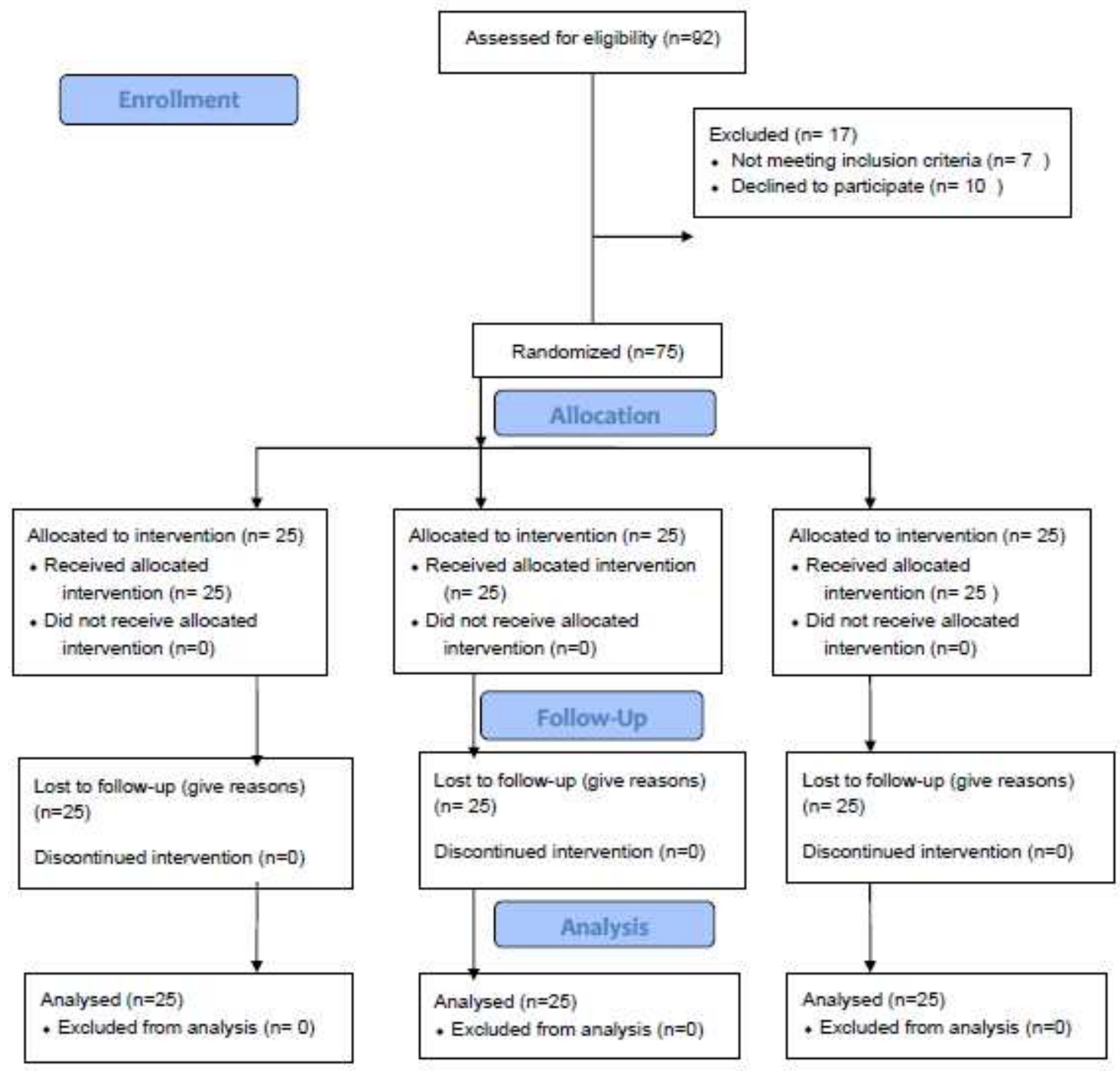

Figure 1

CONSORT diagram showing the flow of participants 


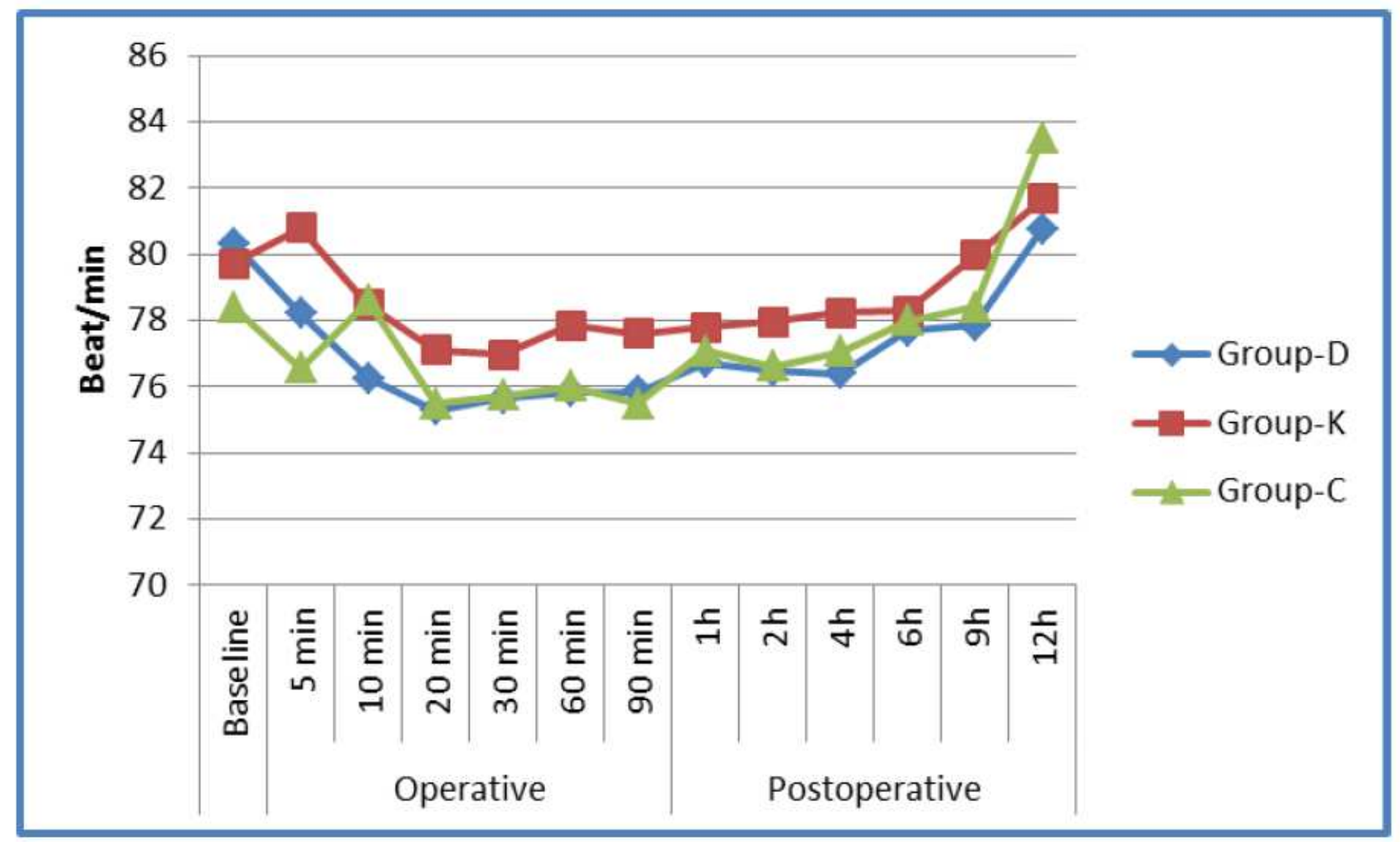

Figure 2

Heart rate changes in the study groups 


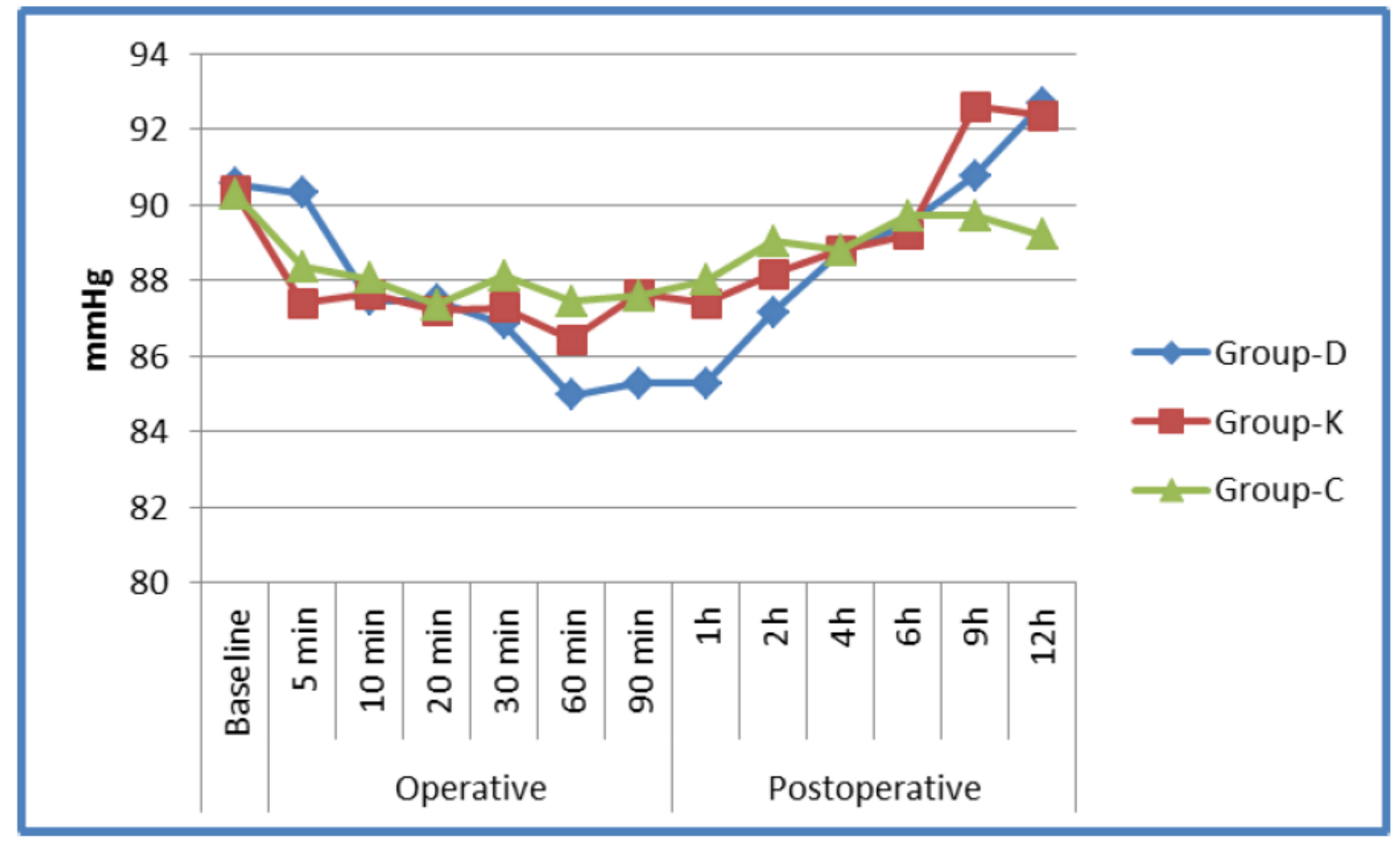

Figure 3

Mean arterial pressure changes in the study groups 


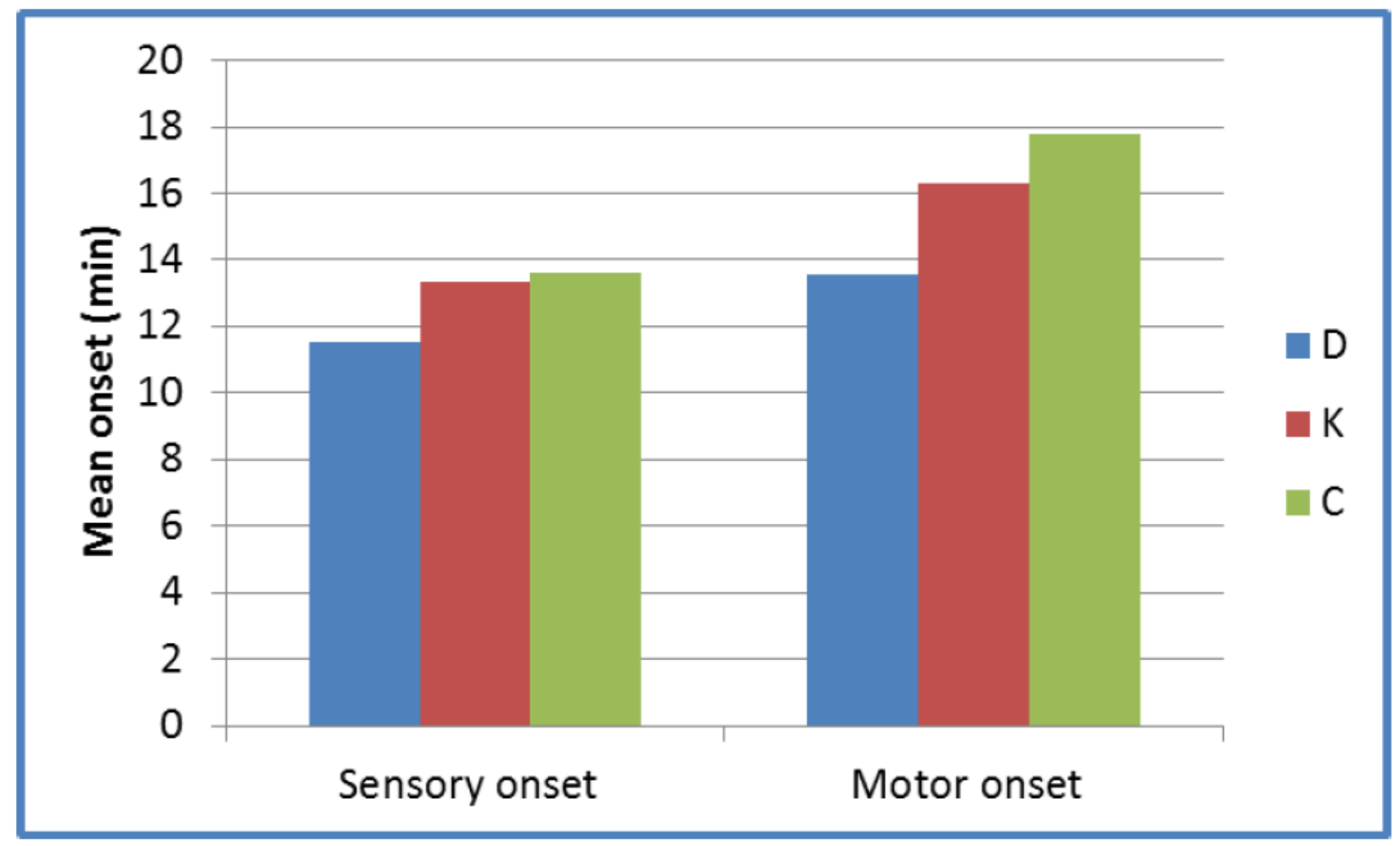

Figure 4

mean time to sensory and motor block onset in the study groups. 


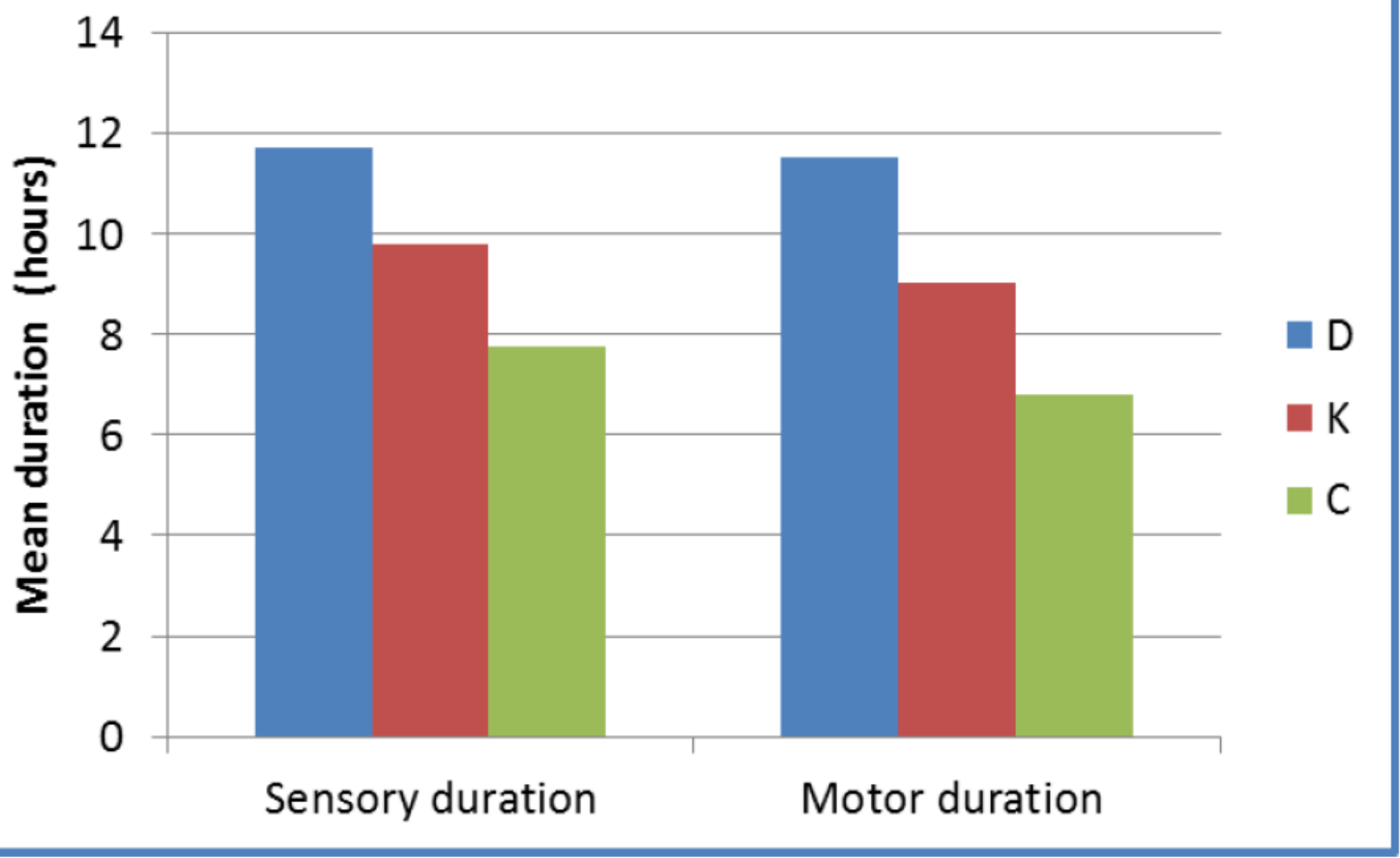

Figure 5

mean sensory and motor block duration in the study groups. 


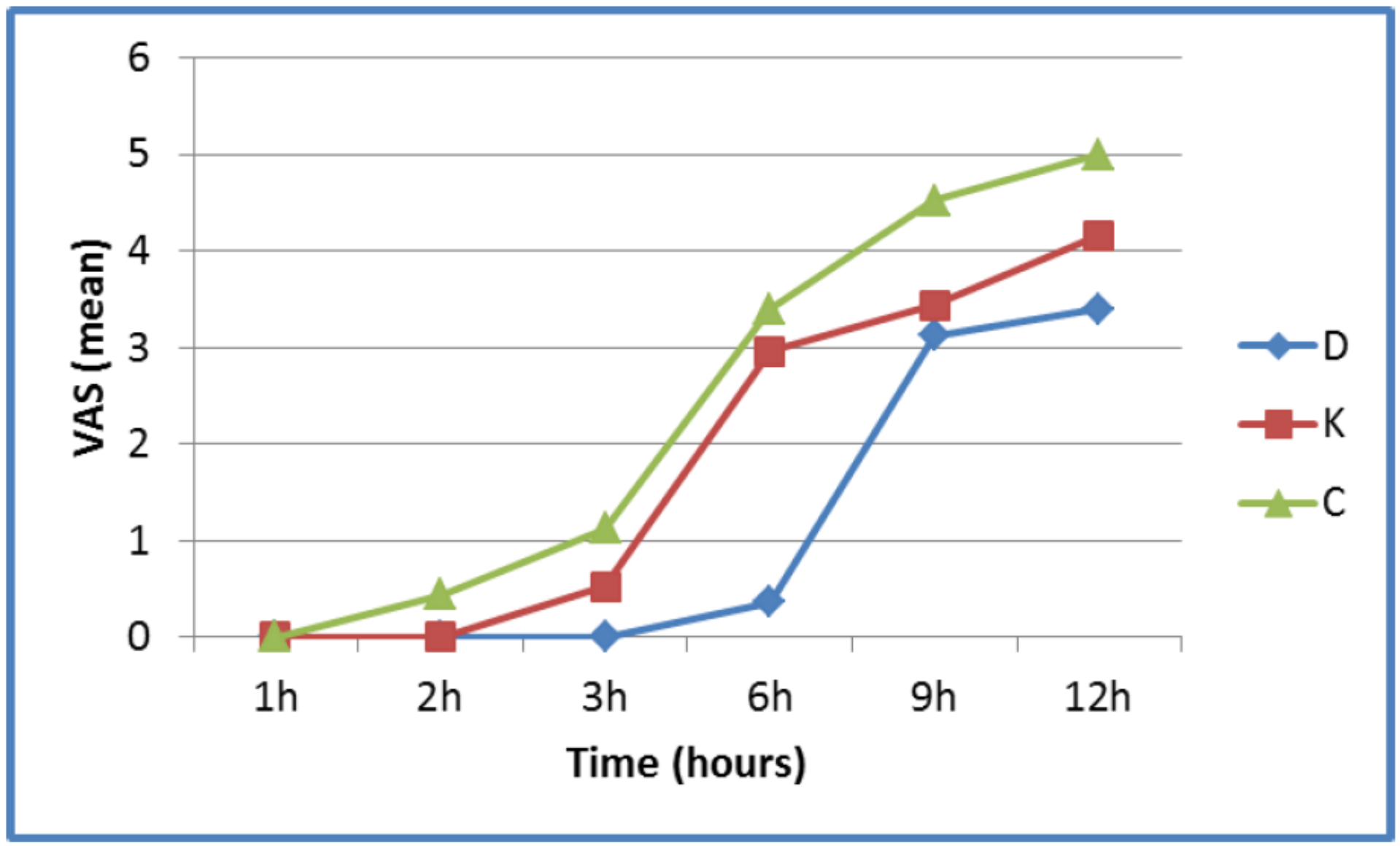

Figure 6

mean post-operative VAS in the study groups. 


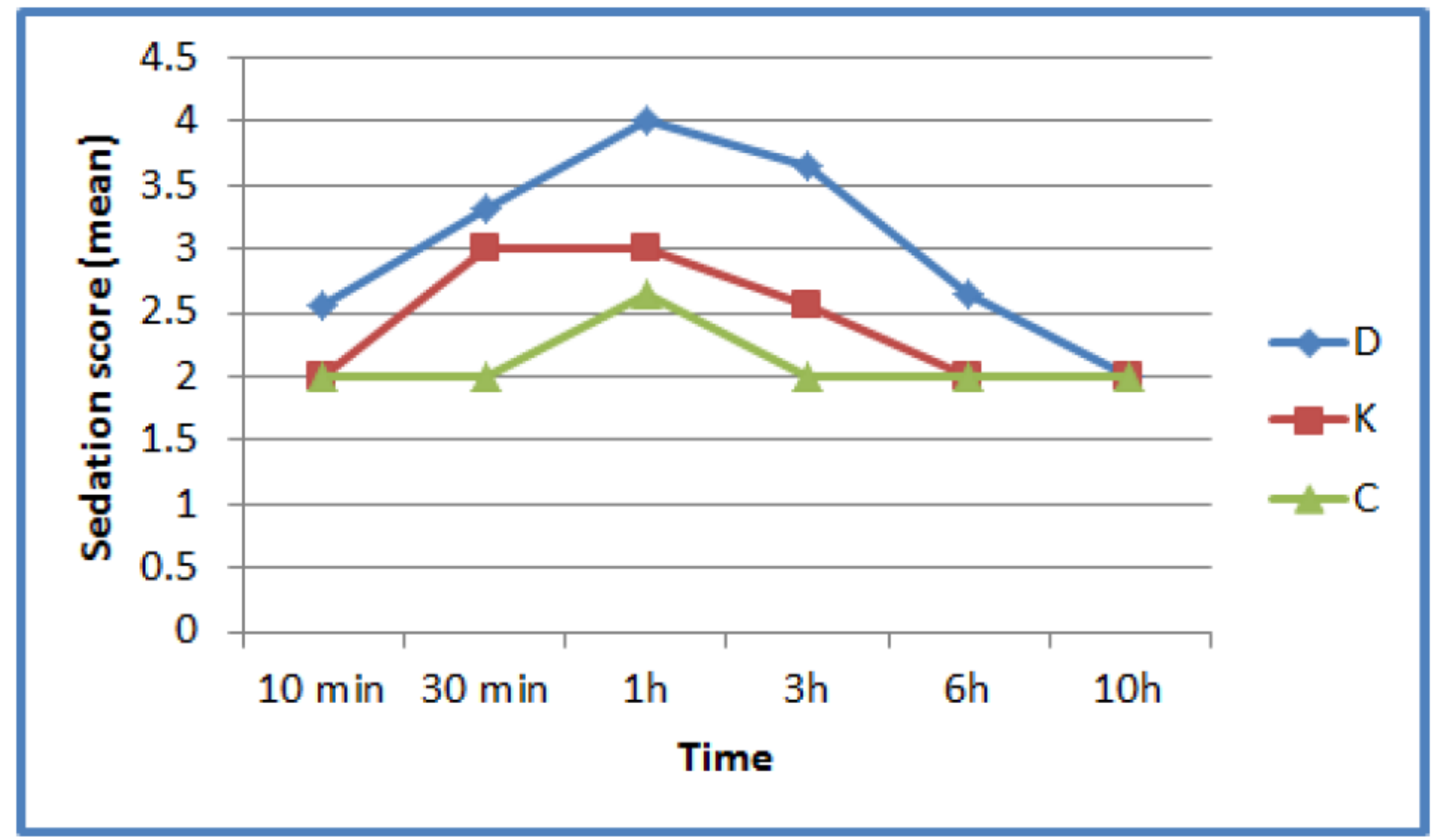

Figure 7

mean sedation score in the study groups. 